\title{
Army Boost Phase Intercept Initiative
}

E. V: George

W. R. Sooy

M. A. Summers

July 28, 1995

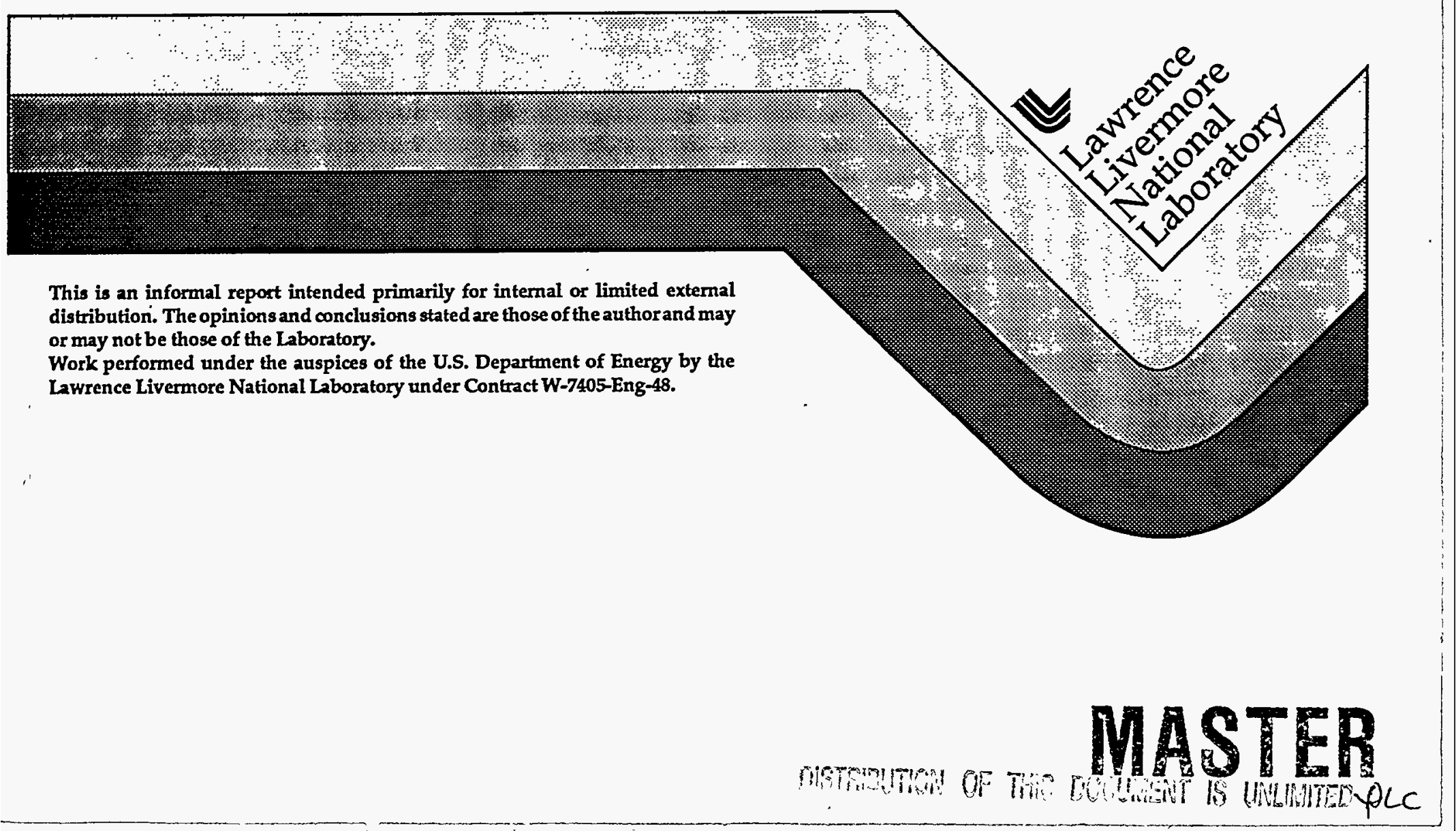


This documerit was prepared as an acoount of work sponsored by an agency of the United States Government. Neither the United States Government nor the University of California not any of their employees, makes any warranty; express or implied, or assumes any legal liability or responsibility for the accuracy, completeness, or usefulness of any information, apparatus, product, or process disclosed, or represents that its use would not infringe privately owned rights. Reference herein to any specific commercial product, process, or service by trade name, trademark, manufacturer, or otherwise, does not necessarily constitute or imply its endorsement, recommendation, or favoring by the United States Government or the University of California. The views and opinions of authors expressed herein do not necessarily state or reflect those of the United States Covernment or the University of California, and shall not be used for advertising or.product endorsement purposes.

This report has been reproduced - diriectly from the best available copy.

Available to DOE and DOE contractors from the Office of Scientific and Technical Information : P.O. Box 62, Oak Ridge, TN 37831

Prices available from (615) 576-8401, FTS 626-8401

Available to the public from the

National Technical Information Service

U.S. Department of Commerce

5285 Port:Royal Rd.,

. . Springfield, VA 22161 . 


\section{Army Boost Phase Intercept Initiative}

In 1994 the Department of Defense led an interagency study that identified boost phase intercept (BPI) of theater ballistic missiles (TBMs) as having critical counter-proliferation capability. Although this defensive capability requires further development, the counter-proliferation value of BPI is apparent and stems from its ability to cause TBM warheads to fall short of their intended targets. In some cases the TBMs deliver their payloads onto their own territory. The possibility that these warheads will fall upon a launcher's own assets and per-. sonnel might act as a deterrence to their use.

There is also the ever-present possibility that TBM warheads might be modified to deliver large numbers of chemical or biological submunitions after boost phase is completed. Warhead modification is straightforward and could be implemented in the very near future. Such modification would effectively saturate defensive systems that engage TBMs in the midcourse or terminal phase of their flight. The early deployment threat can be defeated only by destroying the TBMs prior to launch or during their boost phase.

There are two types of weapons that can be employed to attack and destroy TBMs in their boost phase: laser weapons and kinetic energy hit-to-kill missiles.

Laser weapons can be deployed on aircraft or on satellites. The Air Force's Airborne Laser (ABL) program and Ballistic Missile Defense Organization's (BMDO) Space-Based Laser (SBL) program are both directed at this application. The ABL program is developing a large, chemically powered laser weapon to be carried in a Boeing 747 aircraft at 42,000 feet. It will be deployed in.theater, stationed over safe territory, and have sufficient range to fire into TBM launch areas. The SBL program is developing a different type of chemically powered laser weapon to be placed in orbit at an altitude of 744-868 miles (1200-1400 km). A suitable constellation of SBLs should provide defensive firepower in any likely future warfare locations.

To deal effectively with a Desert Storm-type conflict would require approximately $5-10$ ABLs or 12-20 SBLs. The 10-year life cycle costs for these approaches are approximately $\$ 5 \mathrm{~B}-\$ 6 \mathrm{~B}$ for the ABL and \$17B-\$23B for the $\mathrm{SBL}$. Both the $\mathrm{ABL}$ and the SBL will require about 10 years to reach the demonstration and limited operational capability point, and $3-5$ years more to achieve initial operational capability.

The technology for hit-to-kill missiles is more mature than the laser weapon technology and could provide a capability well before ABL or SBL. Until this year the Air Force and BMDO had a joint development program for a BPI missile, but the Air Force redefined its program priorities and cut its contribution. The Senate Armed Services Committee, in its FY 96 authorization language, "remains highly skeptical about a BPI system based on manned tactical aircraft" and recommended using high-altitude, long-endurance, unmanned aerial vehicles (UAV) as the platform.

This alternative BPI missile concept recently proposed by the Army, revives an architecture developed by Lawrence Livermore National Laboratory. This alternative requires significantly fewer airframes than the fighter-based approach because of the long loiter times of the UAVs. Approximately $20 \mathrm{UAV}$ platforms would be required to deal with a Desert Storm-type. conflict. Another advantage of the UAV concept is the absence of pilot risk and the consequent flexibility to patrol the UAVs deep into enemy territory where they can engage the launches of the longer range TBMs.

The 10-year life cycle cost for this concept is estimated to be $\$ 1.5 \mathrm{~B}$, much less than the alternative approaches. Of equal or greater importance is the projected time-to-deployment. The threat from TBMs carrying advanced submunitions is near term; the laser weapon solutions are 10-15 years away, but the hit-to-kill missile solution can be realized in limited operational capability in 5 years and initial operational capability in 7 years.

The UAV concept makes use of the highàltitude, long-endurance platforms being developed by the Defense Airborne Reconnaissance Office (DARO). These UAVs would carry 3-6 light-weight BPI missiles and be able to loiter 


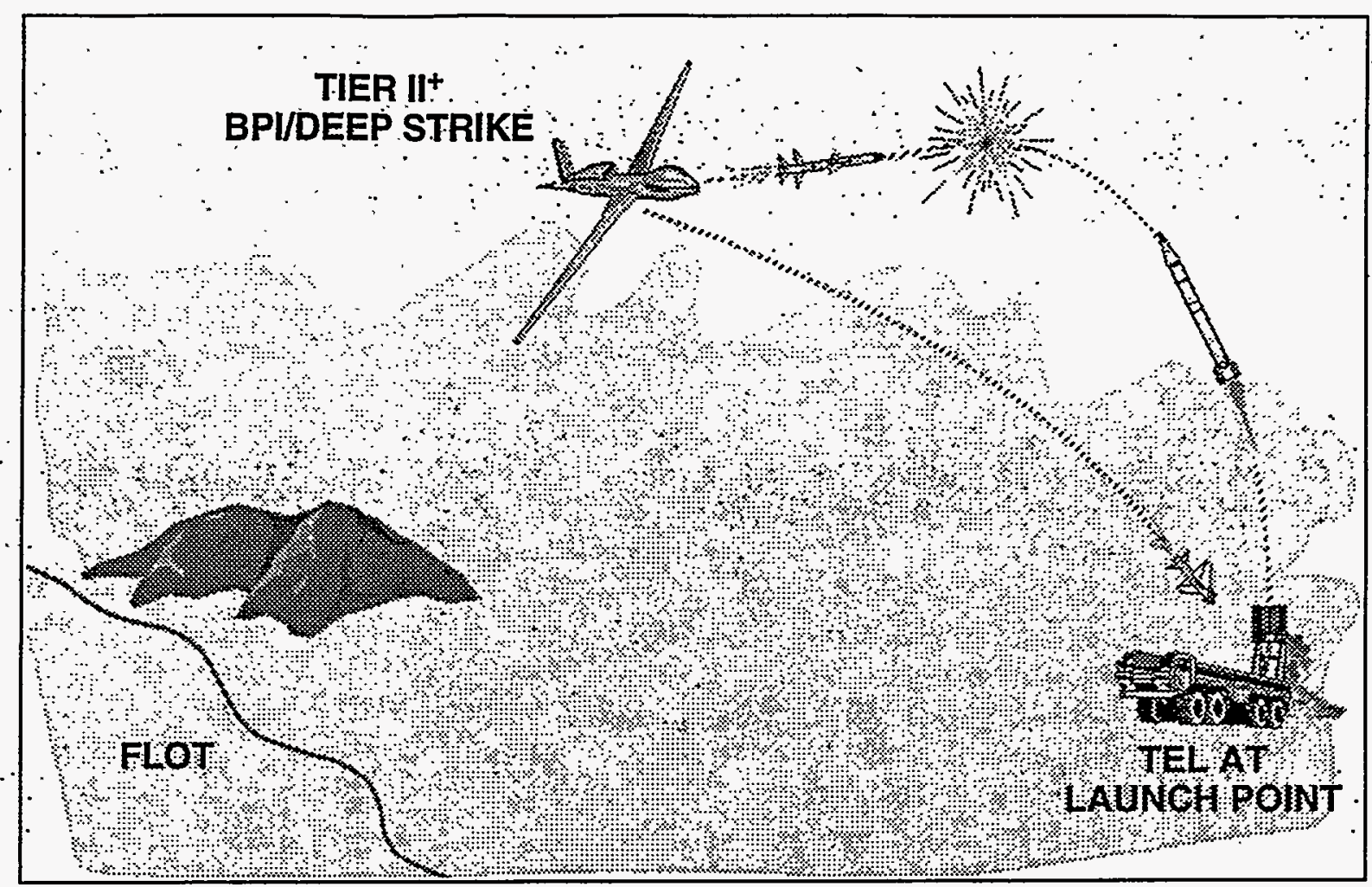

99-00-0795-1751pb01

on patrol at 65,000 feet for 48 hours. The UAV would be equipped with self-defense electronic counter measures, sensors for threat acquisition, communications for cueing, midcourse missile control, mission command and control, and networking with other UAVs. The deployment concept is shown in the figure below.

UAVs can also play an additional.role by supporting deep strike operations. Since they. will be patrolling over enemy launch sites they will be positioned to deliver quick-response attacks against TBM transporter-erector-launchers. In this role the UAVs would carry a modified (extended range) version of one of the current tactical antivehicle missiles, either in place of the BPI missiles, or in a mixed payload.

The proposed UAV/BPI program would be sponsored by the Office of the Secretary of Defence Counter-proliferation Office and managed by the US Army Space and Strategic Defense Command. Technical support would come from Lawrence Livermore National Laboratory. It will proceed in close coordination with BMDO, which has been developing the BPI interceptor hit-to-kill warhead in the
Atmospheric Interceptor Technology (AIT) program, and with DARO, which is developing the UAV platforms and relevant sensor payloads.

The program will proceed through two major milestones. The first milestone will be in the third year with a demonstration of the BPI missile effectiveness. The demonstration will . involve BPI missiles launched from high-altitude aircraft that will lethally engage target TBMs at mission-relevant ranges. The second milestone in the fifth year will be a demonstration of integrated system capability where BPI missiles will be launched from UAVs in realistic scenarios. The equipment from milestone two will provide limited operational capability for emergency employment. Initial operational capability should be achieved two years following milestone two..

In addition to the ongoing. BMDO investment in AIT development and the DARO investment in UAV and sensor development, this BPI development program will cost approximately $\$ 200 \mathrm{M}$ over a 5-year period with $\$ 25 \mathrm{M}$ funding required in the first year. 
Technical Information Department - Lawrence Livermore National Laboratory University of California • Livermore, California 94551

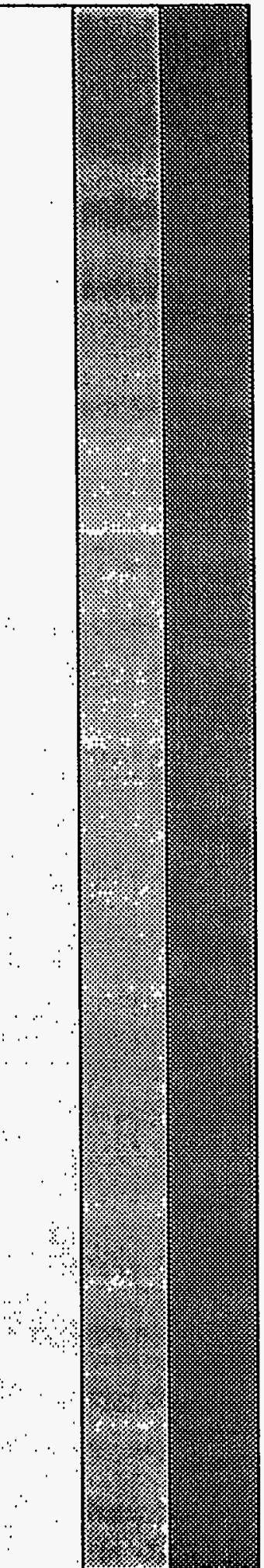

